e-ISSN: $1984-4255 \quad$ ARGUMENTOS

D0I: $10.36517 /$ Argumentos.25.18

\title{
A filosofia de Matias Aires: uma ciência do tempo? ${ }^{1}$
}

\section{The philosophy of Matias Aires: a science of time?}

\author{
Luís Manuel A. V. Bernardo \\ https://orcid.org/0000-0002-3587-7799 - E-mail: Im.bernardo@fcsh.unl.pt
}

\begin{abstract}
RESUMO
Neste artigo, defendemos que a coerência da obra de Matias Aires (São Paulo, 1705-Agualva, 1763) decorre do modo como entendeu a experiência metafísica do tempo. Numa primeira parte, estabelecemos uma espécie de regime de contrariedade entre o percurso biográfico e a sequência das vaidades criticadas para deduzirmos esse fundo experiencial. Num segundo momento, mostramos como este opera nas Reflexões sobre a Vaidade dos Homens, sua obra prima. Por fim, concluímos, identificando a presença dessa mesma inquietude na relativa indecisão sobre as alternativas ao império da vaidade.
\end{abstract}

Palavras-chave: Matias Aires. Ilustração Portuguesa e Brasileira. Filosofia Moral. Filosofia da Cultura. Neo-Estoicismo. Tempo.

\begin{abstract}
Matias Aires's (São Paulo, 1705-Agualva, 1763) was a prominent figure in the Portuguese and Brazilian Enlightenment. In this article, we argue that the coherence of his work stems from the way he understood the metaphysical experience of time. In the first part, we establish a kind of contradiction between the biographical path and the sequence of the vanities criticized in order to deduce this experiential philosophic ground. In a second moment, we show how it
\end{abstract}

\footnotetext{
1 Uma versão embrionária das duas primeiras partes deste artigo encontra-se nos dois contributos do autor para o Dicionário Crítico de Filosofia Portuguesa, indicados nas Referências.
} 
operates in Reflexões sobre a Vaidade dos Homens, his masterpiece. Finally, we conclude, identifying the presence of this same concern in the relative indecision about alternatives to the empire of vanity.

Keywords: Matias Aires. Portuguese and Brazilian Enlightenment. Ethics. Philosophy of Culture. Neo-Stoicism. Time.

L'œuvre dure en tant qu'elle est capable de paraître tout autre que son auteur l'avait faite. Elle dure pour s'être transformée, et pour autant qu'elle était capable de mille transformations et interprétations.

Paul Valéry, Euvres, T. II, Paris, Gallimard, 1960, p. 561.

"A inconstância nos serve de alívio, e desoprime, porque a firmeza é como um peso, que não podemos suportar sempre, por mais que seja leve; e com efeito como podem as nossas ideias serem fixas, e sempre as mesmas, se nós sempre vamos sendo outros?" (RVH, §81). Esta máxima, retirada da sua obra prima, publicada em 1752, Reflexões sobre a Vaidade dos Homens, poderia certamente servir de epígrafe à biografia de Matias Aires Ramos da Silva Eça. Com efeito, a sua vida foi bastante acidentada, patenteando gritantes contrastes com muitas das posições defendidas nessa sua obra, se bem que acabando por confirmar a convicção principal, que a anima, de que, no que diz respeito à existência humana, a vaidade impera sempre. As sucessivas reformulações do seu nome completo constituem por si só um símbolo do que terá constituído um certo desconforto existencial, resultante do conflito entre as imposições do status quo para quem quisesse, como ele quis, ascender socialmente no paço, e a consciência aguda da vacuidade moral desse ritualismo. Seguiremos essas contradições, de modo a evocar panoramicamente traços da vida e da obra.

Matias Aires nasce em São Paulo no ano de 1705 e aí permanece até aos 11 anos. Se as origens familiares foram modestas e provincianas, os negócios do pai, nomeadamente com o comércio de diamantes, já as haviam redimido. Chegado a Lisboa, com a família, em 1716, recebe uma educação esmerada com vista à vida de sociedade, onde, segundo as aspirações de seu pai, deveria figurar já com título nobiliárquico. A nobilitação será uma obsessão comum ao pai e ao filho. Esta foi levada às últimas consequências numa cláusula do testamento do segundo, com a qual pretendia impedir o acesso à herança a qualquer sucessor que não procurasse casamento com pessoa de condição nobre. Decisão que se oferece numa aparente contraposição à crítica demolidora da "vaidade da origem" (RVH, §138 e ss.). Aí, a sua argumentação consiste em reduzir o sangue à sua condição de mero fluído orgânico, material de que a natureza se serve para a produção de qualquer animal, assim como em atribuir um carácter de ficção à historiografia genealógica, concluindo com virulência: "assim, bem podemos assentar, que a vaidade da Nobreza é uma introdução supersticiosa, a qual nasce da vaidade do luxo, da vaidade da arrogância, e da vaidade da fortuna" (RVH, §139). Aparente, contudo, por visar a genealogia, que não o estado, propriamente dito, pois, como argumentou, "assim é, mas quem há-de haver que negue, que a Nobreza, ou essa cousa vã, é útil, necessária, e bem imaginada?" (RVH, §161). Toda a questão se decide, então, entre linhagem e mérito, ainda que este possa surgir 
com os ornamentos do arrivismo. Foi, por conseguinte, com alívio e vaidade que recebeu, em 1729 , numa segunda tentativa apoiada pelo devido investimento financeiro, o hábito de Cristo, e que, após o falecimento do pai herdou o direito a usar brasão de família.

Em abril de 1723, recebia o grau de Bacharel em Artes da Universidade de Coimbra, ao mesmo tempo que, tendo sido admitido como sócio da Academia dos Aplicados, criada um ano antes, se estreava no domínio da poesia, com um soneto dedicado ao teatino Rafael Bluteau (1638-1734), um dos patronos culturais de relevo.

O que poderia haver de auspicioso nestas primícias foi interrompido, em 1727, por um episódio com foros de escândalo, surpreendente para quem virá a pugnar pela igualdade antropológica ( $\mathrm{RVH}, \S 79)$, produzindo, mesmo, uma diatribe, clara na argumentação, embora ambígua nas conclusões, contra a escravidão provocada pelo despotismo fora da Europa (RVH, §126). Tendo, por razões desconhecidas, golpeado a língua de uma escrava, foi condenado a quatro anos de degredo para o couto de Castro Marim.

Ainda que a pena tenha sido perdoada por D. João V, preferiu partir para a Europa (seriam as Lettres bohémiennes, de que só nos resta a menção da edição na década de 50, uma lembrança desse périplo?), viagem que lhe permitiu aprender grego e hebraico, iniciar-se no âmbito das ciências e concluir, em Paris, a licenciatura em Direito Civil e em Direito Canónico. $O$ gosto pelas línguas antigas motivou-o a empreender traduções de Quinto Cúrcio, de Lucano e das "Vidas Paralelas de Alexandre e César" de Plutarco, trabalhos que interrompeu de moto próprio, conforme indica no "Prólogo ao Leitor" das Reflexões (RVH, p. 38).

Essa estadia tê-lo-á introduzido, ou confirmado, na corrente filosófica dos moralistas seiscentistas, na qual avultam nomes como Pascal, La Bruyère e La Rochefoucault (1613-1680) e obras, respetivamente, como Pensamentos, Os Caracteres e as Reflexões, Máximas e Sentenças. No convívio prolongado dessas propostas filosóficas, nas quais se cruzam, entre outros, o legado do moralismo crítico do humanismo renascentista, nomeadamente na sua aplicação à cultura cortesã, o jansenismo e o neoestoicismo, encontrou o esteio para a sua própria. Anos de maturação, levá-lo-ão a desenvolver, nas Reflexões, alguns aspetos contidos nessas referências, num registo que, indubitavelmente, as moderniza, antecipando outras apropriações mais tardias, como a de Nietzsche ou a dos Existencialistas cristãos. Diverge, dessa feita, quer do escolasticismo, quer do reformismo ilustrado, situando-se, por isso, ao abrigo das principais polémicas culturais do tempo, mas não do lápis do censor que, em tal escolha, pressente o caráter menos ortodoxo e os efeitos potencialmente sulfurosos da lembrança detalhada de uma vaidade, que multímoda e universal, não admite verdadeira redenção.

De volta a Portugal, em 1733, dedica o seu tempo ao fausto e uma disputa jurídica vitalícia pelo direito à herança da sua irmã Teresa Margarida, que recusara a vida de convento, a que fora votada, por decisão paterna, para contrair matrimónio, e se tornará na autora de Máximas de Virtude e de Formosura, com que Diófanes, Clymeneia, e Hemirena, Príncipes de Tebas, vençerão os mais Apertados Lances da Desgraça (1752), o primeiro romance setecentista escrito por uma mulher em Portugal, fortemente inspirado nas Aventuras de Telémaco de Fénelon (1651-1715), para lá de outros textos de menor impacto. Uma vez mais, estranha postura, tendo em conta que criticará a clausura forçada para as mulheres (RVH, §113-118) e declarará, num óbvio remoque contra o funcionamento da magistratura, que, nos juízes, enquanto homens comuns, "a injustiça é quási natural" (RVH, § 133).

Entretanto, com a morte do pai, em 1743, sucede-lhe no cargo de Provedor da Casa da Moeda, mas não perde a senha persecutória relativamente à irmã, por improcedente que esta se revele. O carácter tutelar da figura paterna ter-lhe-á inspirado a redação de um Discours panégyrique sur la vie et les actions de Joseph Ramos da Silva, entretanto desaparecido, tendo ficado a referência à sua publicação em 1759 na Biblioteca Lusitana de Barbosa Machado. 
Apesar de manter uma relação de amancebamento com Helena Josefa da Silva, da qual resultaram os seus dois filhos, decide procurar mulher legítima, tendo acabado por se casar por procuração com D. Genoveva de Noronha, casamento anulado por não consumação. Antes, em mais um episódio de romance, pedira a um amigo que lhe arranjasse mulher francesa, mesmo feia e desenxabida, com a única condição de desconhecer completamente o mundo. Procedimento na moda, à época, como salientam os historiadores, mas que, por isso, não deixa de suscitar alguma perplexidade quando se medita as páginas entusiásticas que escreveu sobre o papel fundamental do amor. Este seria o único rival da vaidade universal, à vez, força de conservação da natureza (RVH, §98); manifestação da estrutura desiderativa complexa do humano, que nos impele para uma existência sempre exterior ( $\mathrm{RVH}$, §94); misto de instinto, violência passional, vaidade, inconstância, antecipação imaginativa; antítese dialética entre esperança e concretização; jogo entre Eros e Thanatos (RVH, 106); configuração antropológica do desejo orientado para a formosura ( $\mathrm{RVH}, \S 105)$ e expressão de liberdade do querer que só tem par na força inventiva da imaginação (RVH, §114).

A década de 50 corresponde ao período de maior produção literária, mercê de uma limitação dos contactos mundanos, com laivos de misantropia e de desencanto com a vida social, de cínica desconfiança, mesmo, que muito devem ao emagrecimento pecuniário, fruto do esbanjamento continuado, como se depreende de várias passagens da Carta sobre a Fortuna, dirigida a um amigo. Para além dos textos referidos, ficou o registo de dois outros títulos: Philosophia rationalis, de que se desconhece o conteúdo, e Problema de Arquitectura Civil, publicado postumamente pelo filho, em 1778. Constituído por dois tomos e um extenso índice de 134 p. com a explicação dos principais termos técnicos utilizados, reflete o intuito propositado de divulgação científica (PAC, I, p. 215; II, p. 18), em nome do moderno conceito de utilidade pública (PAC, II, p. 145), e alardeia um misto de didascália e de erudição sincrética, denunciando os esforços do autodidatismo, em contraponto à severa crítica da vaidade do conhecimento, tida por si pela mais vã de todas as vaidades (RVH, §120). A visão pragmática adotada muito deve, certamente, às marcas do terramoto de 1755 , sobre o qual oferece uma explicação geológica que procura adequar-se ao princípio defendido da neutralidade científica (PAC, II, p. 79 e ss.), sugerindo o alinhamento evidente pela epistemologia moderna, evidência que o conjunto de referências, buscadas na Antiguidade, a intromissão de lugares comuns do imaginário popular, como o da existência da cuva de sapos (PAC, I, p. 57) e a inesperada defesa do geocentrismo acabam por embaciar.

A morte de D. João V em 1750 terá igualmente contribuído para o propalado desânimo, como se depreende do facto de ter incluído um breve, mas eloquente, elogio fúnebre no antepenúltimo parágrafo das reflexões, cujos termos parecem constituir uma espécie de recado cifrado para o novo Monarca (RVH, §161), D. José I. tanto mais que as suas relações com o Marquês de Pombal, seu ministro plenipotenciário, foram sempre conturbadas, o que levou ao seu afastamento do cargo de Provedor, em 1761.

Tais desavenças dariam razão de sobra a que se suspeitasse da autenticidade dos rasgados elogios que endereçou ao Rei, na Dedicatória das Reflexões, bem como na caracterização da figura real, se, para além do mais, a ironia não atravessasse as passagens em que surge, à primeira vista, como indefetível defensor do despotismo esclarecido, em particular na versão ensaiada por D. José. Cabe atentar, a este propósito, no modo como insinua a ideia de uma vaidade real, dada logo no berço, em oposição à dos outros homens, que só se manifesta depois da primeira infância (RVH, §81), tese que acaba por explicitar quando introduz a distinção entre a vaidade dos reis e a vaidade dos outros homens ( $R V H, \S 51-53)$. Essa diferença apresenta-se, outrossim, duplamente balizada, quer pela advertência sobre o risco da tirania, 
quer pelo contraste entre o $\$ 53$ e os $\$ 28-29$, assente na afirmação de que, para os monarcas, "a existência deve ser-lhes menos preciosa do que a fama", já que redunda na vaidade das vaidades, a da memória perpetuada. Acresce que o encómio acaba por ser constantemente contrariado pelas posições doutrinárias de fundo em matéria política. Estas, assentes na tese de que "nascem os homens iguais" com o corolário de que "o mundo não foi feito mais em benefício de uns, que de outros: para todos é o mesmo; e para o uso dele todos têm igual direito" (RVH, §79), apontam para uma conceção republicana, no sentido filosófico do termo, favorecendo os princípios do Estado de direito, que não do poder ou da força (RVH, §131), da vontade geral e da organização comunitária.

Faleceu no ano de 1763, em Agualva, localidade entre Lisboa e Sintra, onde se isolara, com o pretexto de fugir das agruras do mundo para se dedicar a atividades de recreação intelectual, como as experiências químicas que levou a cabo no laboratório que aí montou. Vaidade derradeira, essa de um isolamento forçado que, como o demonstra a obra, no ato de renegar as vaidades mundanas, sabe que mantém secretamente em vigência o essencial do que abjurou: "A vaidade nos inspira aquele modo de vingança e parece, com efeito, que o deixar o mundo é desprezá-lo. Assim será, mas quem deseja vingar-se ainda ama e quem se mostra ofendido ainda quer [...]. Mudamos de lugar, mas não mudamos de mundo" (RVH, §20).

Esta estratégia de renúncia, face a um ambiente em que, progressivamente, tudo lhe foi falhando, e que se lhe impôs como um teatro de vaidades inquebrantável, no qual, contudo, não deixou de participar, foi acompanhada da produção literária da personagem que queria que o representasse para a posteridade, a de um homem íntegro e sem fingimentos (CF, p. 205). Um tal retrato, pese embora o sentimentalismo das tonalidades confessionais, oferece-se como um desfecho conciliador ficcionado para a profunda contradição entre o que foi querendo e o que considerou dever querer, entre a condenação a ser o eu que se é e a vontade de se lhe escapar (RVH, §37 e 75), esbatendo até ao limite a fronteira entre a personagem "real" e a "composta", o homem do mundo e aquele que se lhe opõe no uso da autoria, dando corpo à ideia de que "um homem às avessas seria um homem perfeito" (RVH, §75).

Artifício supremo, no que respeita ao percurso biográfico, no qual cabe identificar, outrossim, a proposta filosófica de uma saída possível do profundo dilema formado pelo círculo comprovado de uma vaidade totalitária. Nesse exemplum, idealizado contra o espectro do acaso e da vacuidade (p. ex., RVH, §45), em que apresentava o viático para aceder a uma existência enfim real, longe da cena desse teatro de sombras ( $\mathrm{RVH}, \$ 29)$, que se dedicou a denunciar, Matias Aires sugeria um retorno à Natureza, entendida como um plano de autenticidade egotista, contraposto ao delírio das interações mundanas. Deste modo, seguia o conspecto neoestóico, participando nessa linha que vai de Baltasar Grácian (1601-1668) a Jean-Jacques Rousseau (1712-1778), ao longo da qual se dá a passagem histórica do acento posto no theatrum mundi, no qual a sobrevivência individual depende do amor próprio e da capacidade para entrar no grande jogo da sociabilidade, para a valorização da cura solitária de um si-mesmo como único antídoto da alienação e da desmoralização sociais.

Com tal reorientação do seu pensar para a aprendizagem de uma cultura de si-mesmo, moldada na ideia de um eterno presente, como interrupção forçada do fluxo das paixões, afastava definitivamente o estribo formado pelo conceito de natureza decaída, ainda a operar no agostinianismo de La Rochefoucauld, deixando o eu entregue à sua autonomia, assim resgatada, à liberdade permitida pela solidão e à sua responsabilidade pelo cuidado desse modo de ser recém descoberto. Porém, nesse aparente desvio, que, na realidade, configura uma das estruturas em movimento da matriz filosófica que escolheu, bem como da sua versão peculiar do modelo, confirmava a dominância de uma experiência ontológica crucial na raiz do seu cons- 
pecto, e, por isso, detetável em cada uma das obras: a experiência da "voracidade cruel do tempo" (RVH, §28).

Terá sido essa consciência aguda de um precipício temporal potencialmente aniquilador, avassaladora nas suas potenciais consequências niilistas, que o levou a desenvolver uma hermenêutica de cariz dialético, na qual ecoam fragmentos de Heraclito e se prenuncia a crítica dos valores nietzschiana, em passagens como a seguinte: "o nosso engenho todo se esforça em pôr as cousas em uma perspetiva tal, que vistas de um certo modo, fiquem parecendo o que nós queremos, que elas sejam, e não o que elas são" (RVH, §117). Esta apresenta-se diversa, na sua complexidade, da estrutura sintática da máxima moralista, meramente comparativa ou desmistificadora, e aposta, preferencialmente, numa analítica de feição genealógica e perspetivista, "porque no tempo também há um ponto de perspetiva, donde como em espelho vão crescendo todos os objetos, e em chegando a um certo termo, desaparecem" (RVH, §42).

Esse sentimento de irrealidade ( $\mathrm{RVH}, \S 4)$, determinado pelo hiato incomensurável entre tempo e eternidade ( $\mathrm{RVH}, \S 162)$, situa-se na raiz da polaridade inerente à vaidade, boa e má, consoante o efeito visado, bem como na circularidade que a torna irrecusável, e condiciona uma mole de intervalos existenciais, que vaidades ou amores deverão preencher: um desacerto ontológico, que está manifesto na diferença já indicada entre natureza e mundo (RVH, §9), espaço/tempo preenchido pelo jogo de representações designado com o termo vaidade; um desconcerto existencial, ilusão de duração e de ação (RVH, §26-28), que não sobrevive, mesmo quando a vaidade se converte em esperança e se projeta numa antecipação de uma lembrança perene ( $\mathrm{RVH}, \S 41)$, à evidência da morte e do esquecimento (RVH, §1-2; p. 79); uma distância relativamente a uma origem em si mesma indiferente ao curso da história da humanidade, desvio que torna ridícula a ideia de uma história universal única $(\mathrm{RVH}, \S 26)$, ponto de fuga, de cujo efeito delirante só escapamos por um estranho jogo entre desengano e atribuição de valor ao que amamos (RVH, §48); uma duplicidade constitutiva, que nos faz ser, sempre, outro de nós, mas também, outro dos outros (RVH, §27), erraticidade que seria interrompida se fosse viável um regresso à inocência, de que o recolhimento do ermita é a possível aproximação $(\mathrm{RVH}, \S 71)$; uma disfunção representativa, que nos impede de quebrar o revestimento especular, seja porque a nossa razão não tem a capacidade de unir as duas lógicas contrárias, a das causas e a dos efeitos (RVH, §9), seja pela necessária transposição do ser em valor, que resulta da prevalência do desejo sobre o entendimento (RVH, §56; p. 74).

Se a meditação dessa vivência só obtém uma tal envergadura filosófica nas Reflexões, voltamos a encontrá-la na Carta, aí vertida, sobretudo, nas figurações com que se apresenta ao eu: transitoriedade e fugacidade da vida (CF, p. 201; 211); medo da morte, com as sequentes antecipação e habituação ao pressentido porvir (CF, p. 211-212), disciplina, de influência helenística, visando a ataraxia e a apatia (CF, p. 208), negação tentada da dor do tempo que se escoa impreterivelmente; tragicomédia do acaso, que subverte a lógica do kairós, baralhando os tempos de receção da fortuna, a qual advindo demasiado cedo não é apreciada e demasiado tarde não é eleita, drama de tirantes entre a fortuna destinada e aquela conquistada (CF, p. 194).

De igual modo, como sugerimos, foi a obsessão pela passagem do tempo (PAC, I, p. 19), considerada como princípio de ação da Natureza (PAC, I, p. 61), com a consequente perda de ser e a intromissão de um fator de imprevisibilidade, que terá motivado o Problema de Arquitectura: "porque razão os edifícios antigos tinham, e têm mais duração do que os modernos? E estes porque razão resistem menos ao movimento da terra quando treme?" (PAC, I, p. 1). Processo que o progresso científico deveria inverter (PAC, I, p. 121), mas que a força inexorável da temporalidade impede de reverter totalmente à força produtiva originária, forçando a humildade de reconhecer que "a Física, cuja verdade é infalível, é aquela que consta da Sagrada História" (PAC, II, p. 23). 
Aqui, essa dinâmica temporal surge plasmada nos processos particulares da matéria: desgaste, enfraquecimento, tibieza, dissolução, corrupção e o que cabe ao homem é a gestão da incessante decrepitude. Por sua vez, os terramotos darão azo a que o autor entrose especificamente os três planos de temporalidade (da Natureza, da Vida e da Arte) com o fio da Morte: "no caso dos terremotos, quantos perdem a vida por um minuto de menos, quantos morrem porque não tiveram um instante demais! Sendo o tempo precioso, quanto não será aquele de que depende a morte de muitos, ou a vida!" (PAC, II, p. 5).

Por entre longos excursos sobre temas de química, física, agricultura, medicina, farmácia, engenharia, geologia, e a proposta de um suposto novo sistema baseado no que julgou detetar como a parte glutinosa da água, em oposição às conceções assentes na ideia da existência de um elemento nitroso (PAC, II, p. 48), a solução que deu ao problema revelava, não obstante a aparente redundância para o domínio em causa, a dupla maneira que entendia adequada, em qualquer plano, para fazer frente à derrocada do tempo: por um lado, a insistência na importância dos materiais, corresponde à convicção geral, mesmo no âmbito da antropologia, de que só nos cabe gerir a ordem dos efeitos, pensada na linha do mecanicismo cartesiano (RVH, §90); por outro, o lugar conferido ao agir, enquanto imitação da produção natural, retoma, à sua maneira, a conceção da natureza como símile da eternidade, ao contrário da evanescência do Mundo (RVH, §162).

Como concluíamos num artigo sobre esta obra:

Desta feita, as dificuldades da Arquitetura são semelhantes às dificuldades de construir uma vida, biologicamente saudável, e, eticamente, com sentido: como projetar o futuro se temos a certeza do fim? Como gerir a fragilidade de um organismo que, todos os dias, decai? [...] Como evitar que sobrevenha a morte demasiado cedo para a tarefa de construção do caráter pelo qual havemos de ser julgados na outra vida? Como, enfim, quebrar a lógica das vaidades, nem que fosse por um instante, o qual, como um lampejo de felicidade, provocaria um corte significativo $n$ texto que todos julgamos ter a obrigação de representar? (BERNARDO, 2008, p. 468).

Solução que, a existir, será sempre provisória e à medida do homem, pois, como lembrava, com um pessimismo característico dos defensores das morais assentes na valoração, para "a farsa desta vida", só há um desfecho terminativo: "a morte que está de sentinela, em uma mão tem o relógio do tempo, na outra tem a fouce fatal, e com esta de um golpe certo, e inevitável, dá fim à tragédia, corre a cortina, e desaparece" (RVH, §79). Pessimismo ou lucidez?

"Tudo no mundo é vão, por isso a vaidade é a que move os nossos passos" (RVH, §20).

Relativamente à compreensão do sentido filosófico da sua obra maior, Reflexões sobre a Vaidade dos Homens, impõe-se fazer, por conseguinte, uma triagem hermenêutica, em função, precisamente, da experiência capital da temporalidade, por nós identificada. Descontando as explicações pela biografia, pelo contexto, pelas influências e respetivos processos de receção, todas válidas, sem que, contudo, permitam incidir sobre a intencionalidade filosófica do propósito, ao intérprete cabe, assim, determinar se as Reflexões visam expor, prioritariamente, uma parénese construída em torno da crítica da vaidade e da procura dos meios para nos libertarmos dos seus efeitos nefastos, tarefa, por si só, tão complexa quanto legítima, pois, como nos lembra 
o autor, "é arte mui dificultosa de aprender aquela que nos tira a presunção" (RVH, §133), o que situaria a obra no domínio da moral, eventualmente assente numa antropologia filosófica, ou se o respetivo alcance supõe, antes de mais, uma intuição metafísica, com consequências na vivência humana, o que implicaria o texto no horizonte do questionamento ontológico.

Não sendo mutuamente exclusivas, respeitados os planos a que se referem, as duas linhas hermenêuticas recortam-se, inevitavelmente, em muitos aspetos. Contudo, o facto de os intérpretes que escolhem um ou outro dos caminhos não chegarem a uma mesma imagem final supõe uma diferença metodológica que importa explicitar. A escolha privilegiada da primeira perspetiva valoriza o termo arte, de modo que as Reflexões surgem, sobretudo, como resultado de um exercício combinado de suspeita e afundamento, baseado na crítica social e na análise psicológica da natureza humana (RVH, §136), que visa reformar a sociedade e os indivíduos que a compõem. A opção pela segunda, por nós seguida, na medida em que nos afigurar mais apta a restituir o alcance filosófico da obra, destaca o papel do que o autor designa como ciência do tempo (RVH, §125), a qual impõe um regime de universalidade onde parecia dominar a situação, enquanto valoriza os processos reflexivos de abertura, inquietação e irresolução, que questionam a solidez, previamente vincada, da contextura. Em consequência, mais do que um sistema doutrinário partilhado com o leitor, as Reflexões preveem a necessária participação deste na produção do sentido do que aí se encontra exposto, bem como na eventual eficácia existencial do articulado.

Esta prioridade está, igualmente, conforme ao desenvolvimento de uma antropologia filosófica universal, deduzida da própria universalidade da vaidade, do que esta revela sobre a experiência da finitude e da vacuidade do ser temporal. Um tal projeto, como indicámos previamente, redunda na superação de dois modelos, sobre os quais se alça para se diferenciar: a tradição das obras sobre a vida palaciana, em que o homem a moralizar é, na verdade, o cortesão; a receção secular da teoria agostiniana da natureza decaída, que reconduz a imoralidade ao pecado original, a qual prevê, do mesmo passo, o processo de redenção. $O$ estreitamento suposto na primeira, ainda visível e operativo em certas passagens das Reflexões, é ultrapassado precisamente pelo efeito dessa experiência de uma fragilidade ontológica comum, decorrente da temporalidade inexorável do ser para a morte. Por sua vez, a crítica da vaidade pura, para jogarmos com os termos kantianos, revela-se bastante para dar conta de um dinamismo próprio, autossuficiente e esclarecedor, que evidencia as suas condições transcendentais, mas, que, por isso, deixa de carecer de fundamento absoluto. A visão da segunda também não desaparece, mas, em vez de se dar como premissa da qual se deduz a vaidade, como traço vicioso, ter-se-á de reconstituir a partir dessa nova composição entre temporalidade e vanidade e conseguir conciliar-se com o entendimento da natureza como oikéiosis, relação particular a si e ao mundo, numa versão modernizada do significado que o Estoicismo lhe conferiu.

Nesta linha interpretativa, cabe entender a crítica denunciante como um processo radical alargado de desconstrução, pensado por Matias Aires para quebrar a aparente consistência dos discursos em vigor e patentear o modo como induzem a existência de uma ordem imaginária com valor de realidade. Esta metodologia torna-se necessária por ter de se haver com discursos tipicamente delirantes $(\mathrm{RVH}, \S 14)$, labirínticos $(\mathrm{RVH}, \S 60)$, pela complexidade do jogo de vaidades que encenam, pela perda de identidade a que conduzem e pela confusão de argumentos de que fazem uso, que geram sistemas universais de loucura ( $\mathrm{RVH}, \S 25)$. Estes mostram-se tão enraizados socialmente, que não podem ser combatidos nos seus próprios termos, escorados como estão, ao mesmo tempo, na comparação de estatutos sociais, na influência mútua e na comunicação recíproca ( $\mathrm{RVH}, \S 38)$, mas requerem a adoção de uma atitude de lucidez universal, a qual antecede e extravasa o intento de moralização da humanidade. Esta 
mesma exigência de perspetivação diferenciada e dialética, provocada pelo enfoque constituído pela perceção clara da omnipresença do tempo, influi na própria crítica das vaidades universais, a do sábio, a do magistrado e a do nobre, contrapostas às locais e territoriais (RVH, $\S 88)$, que fecha a obra.

O tratamento da primeira, a vaidade do conhecimento, revela-se, a este propósito, exemplar. Ela surge caracterizada de diversas maneiras: convicção ilusória de perenidade (RVH, §127); indiferença ética por redução axiológica e/ou narcisismo (RVH, §128); efeito de desordem e de confusão, que acarretaria a transposição do modelo da disputa académica para o campo social (RVH, §129), que os sábios não conseguiriam controlar, atendendo à sua incapacidade para governar (RVH, §130). Por sua vez, são-lhe apontadas causas específicas: desconhecimento de si em prol de uma sobrevalorização do que mais não pode ser do que palpite sobre o funcionamento do Universo; confusão entre a ordem das coisas e a das palavras; soberba da erudição, por desconhecimento de que "a maior parte das coisas de que o mundo se compõe, nem se podem ensinar, nem aprender" (RVH, §129). Porém, a razão principal, cujo desconhecimento tolda o acesso à emenda das outras, reside na incompreensão de que a verdadeira ciência é o tempo, porquanto constitui uma espécie de plano de realidade, no qual «cada cousa guarda o seu defeito original» (RVH, §125), que obriga a corrigir a deformação axiológica introduzida pela incapacidade humana de lobrigar o ente na sua identidade (RVH, §90).

Assim, como se depreende, é a mediação da consciência do tempo que circunscreve a ciência humana a uma dimensão narratológica, dessa feita, reconduzida ao único regime cognitivo viável, o conhecimento por comparação, isto é, por defeito, diferença, composição e imperfeição (RVH, §109), longe, portanto, da pura positividade ou do acesso direto à verdade. Levando a ponderar uma eventual influência da Ciência Nova (1725) de Giambattista Vico (1668-1744), prevalece, então, o exercício hermenêutico como processo de interpretação textual, doravante, igualmente, aplicável à fenomenologia da duração, isto é, à trama fictícia da existência mundana, "cerimonial imaginário, mudável, de instituição nacional, e variante" (RVH, §81), único modo de praticar a anamnese da inocência originária ( $\mathrm{RVH}, \S 132)$, rasgando a cortina das representações e patenteando a unidade inquebrantável e remanescente do ser: "na criação do mundo não houve nas águas diferença, só houve divisão; a diversidade só foi no nome, e no lugar, mas não na matéria original [...]. assim são os homens; no seu género têm com as águas um paralelo" (RVH, § 81).

Mas é também a reflexão sobre o tempo que nos conduz ao entendimento do lugar que a vaidade ocupa entre os homens, segundo uma lógica de contrários ( $\mathrm{RVH}, \S 118)$, instrumento cognitivo suscetível de se aplicar com proveito à análise do saber humano, e de evitar que um certo pessimismo ético inevitável, despontando em várias passagens da obra, descambe numa qualquer forma de niilismo. A alternativa otimista, arco que se desenha, como um dos eixos arquitetónicos da obra, da inocência natural à inocência recuperável, decorre da necessidade de se pôr a vaidade em perspetiva ( $\mathrm{RVH}, \S 42)$, acentuando a diversidade das suas expressões: aqui, vista como consolação universal ( $\mathrm{RVH}, \S 2 ; 84)$; ali, fustigada pela vacuidade existencial que admite (RVH, §6); de outro modo, reconhecida enquanto indispensável à afirmação de cada homem face à indiferença igualitária da natureza (RVH, §23-24;79); por fim, dispensada nas figurações que tem assumido na história da humanidade (RVH, §88). Ora, tal só é possível por haver esse ponto de fuga constituído pela eternidade, a partir do qual se define o plano da passagem do tempo. Esta orientação afigura-se comum à Natureza exterior, desta feita caracterizada, intrinsecamente, como conservação, revolução e metamorfose ( $\mathrm{RVH}$, §9), portanto, como espelho temporal da intemporalidade, e à Natureza humana, situada, igualmente, entre tempo e eternidade. Comprova-o, neste caso, o que, no constante esforço para negar a inexo- 
rabilidade do contínuo fluir, intrometendo fatores judicativos redundando na suposição paradoxal de uma vida no tempo contra o tempo $(\mathrm{RVH}, \S 59)$, se oferece como um processo contranatural (RVH, §116).

Podemos, em conformidade, perceber melhor que aquilo de que importa, verdadeiramente, tomar consciência esteja sintetizado nas formulações seguintes: "estamos no mundo para ser alvos do tempo" (RVH, § 85), a tal ponto que "também na vaidade há horas" (RVH, §87). A ação do tempo, analisada pelo prisma do mundo, consiste, assim, numa espécie de inversão do seu efeito natural ( $\mathrm{RVH}, \S 75)$, enquanto a análise do mundo, pelo prisma do tempo, patenteia um conjunto de contradições, no qual se afrontam um processo esquizofrénico de denegação da vida, a favor das múltiplas máscaras da morte, "como se os homens mais nascessem para terem honra, que para terem vida, ou fossem formados menos para existirem no ser, que para durarem na vaidade" (RVH, §4). e a força dessa mesma vida que se afirma no interior das paixões, incluindo a própria vaidade. Essa vitalidade opera de diferentes modos: favorece a construção de uma segunda natureza (RVH, §83), em nome do amor-próprio (RVH, §107), cujo princípio, simultaneamente, vital e mundano, é a sensibilidade, à vez, sentimento e gosto, amor e vaidade ( $\mathrm{RVH}, \S 79)$; gera um conflito entre a espiral narcísica da vaidade e a exigência de conservação (RVH, §60), por via reprodutiva; sugere um esquema conciliador, mediado pelo desejo de beleza, entre a vaidade e o amor, na aceção de amor passional, situado entre o sensual e o divino (RVH, §94). Desta feita, torna-se visível a teleologia inscrita no nosso ser: "as criaturas são mais perfeitas, à proporção que são capazes de mais amor; e assim o amor não só é o princípio da vida, mas também é um sinal de perfeição" (RVH, § 91).

A possibilidade de compreender essa dialética do tempo, quebrando a ilusão tentacular de unicidade própria da ideologia dominante, encontra-se, assim, dependente da determinação de uma zona de conflito no plano passional. Cabe, então, desenvolver as disposições ético-gnosiológicas para se poder decidir se se pretende ser vencido pela vaidade, pelo amor, ou por ambos, solução que o autor preconiza. Este requisito configura um paradoxo que denuncia a duplicidade da vontade humana, na base do tipo de indecisão que deixa lugar ao domínio absoluto da vaidade ( $\mathrm{RVH}, \S 67)$, e instala um regime interno de aporia, que urge resolver antes de qualquer expectativa de ação concertada para minorá-lo; "vimos ao mundo para fugirmos de nós" (RVH, § 75); "nunca podemos fugir de nós" (RVH, §37).

Ainda que, para Matias Aires, só no plano pragmático do agir se imponha uma lógica de eventos que, na crueza do seu acontecer, tem o poder de questionar o delírio retórico da vaidade ( $\mathrm{RVH}, \S 80 ; 86)$, a condição prévia enunciada, a de uma mudança individual, decorre de uma das constatações mais importantes, que se vai insinuando como o segredo do funcionamento do mundo e se oferece como chave para o entendimento do padrão isomórfico que produz a ilusão global de realidade: as mesmas estruturas de idolatria sustentam amor e vaidade, não havendo lugar a qualquer oposição binária, que permita favorecer um em detrimento do outro. É que a existência mundana está sujeita a um princípio de organização e de regulação que não corresponde à objetividade, mas à intersubjetividade, o valor: "o nosso engenho todo se esforça em pôr as cousas em uma perspetiva tal, que vistas de um certo modo, fiquem parecendo o que nós queremos, que elas sejam, e não o que elas são [...] O nosso pensamento não se acomoda às cousas, acomoda-se ao nosso gosto" (RVH, §117). Para o homem, por conseguinte, tudo é valor, nada escapa ao jogo de pontos de vista, à procura de opiniões consensuais, à busca infindável de reconhecimento alheio.

Por isso, se bem que haja lugar para distinguir, num primeiro momento, amor e vaidade, enquanto princípios universais do comportamento humano, um natural outro cultural, o que se revela fulcral é detetar o processo pelo qual, num segundo momento, quando praticados, 
ficam cativos do mesmo olhar, ou seja, passam ao estatuto de forças sociais, esteio passional das relações mundanas. É este o motivo que leva a uma equivalência no funcionamento, no amor reproduzindo-se os mesmos esquemas de ficcionalidade da vaidade: valor da imaginação e do imaginado, contra a evidência da realidade; incapacidade para viver no presente; inconstância; vontade de poder; tensão para o outro (RVH, §106). Uma tal semelhança significa que vaidade e amor não só constituem critérios de valorização, como se convertem, eles próprios, em valores, relativos, por conseguinte, a um fundo que espelham, mas não conseguem anular.

Esse plano fundamental, que ambos concorrem para esconder, ora positiva, ora negativamente, polaridade que, por si só, denunciaria o estatuto de valor, afigura-se, do mesmo passo, como a particularidade do que no homem é a sua pseudonatureza, esse intervalo, sempre por preencher, entre Natureza e História, prega de nada, a dobrar tudo o que é humano, insuportável abismo de negação e esquecimento, mas, sobretudo, de liberdade e responsabilidade: "daqui vem que nascendo todos livres, a liberdade é contra quem os homens têm conspirado mais" (RVH, §116). Estabelecendo o paralelo com a máxima escolástica relativa ao horror do vazio, Matias Aires resumia esta situação contundentemente: "a vaidade tem horror a tudo o que desperta a lembrança da nossa indigência" (RVH, §62). Vaidade e amor imperam, nesta ótica, não tanto pela desproporção entre nada e infinito, como pretendia Pascal (pensamento 230, ed. ref.), quanto pela necessidade de plenificar o vazio que se instala entre nada e nada, quando tudo o que se apresenta é efémero e, em si mesmo, ausente de razoabilidade suficiente.

Deste modo, se fecha o círculo originário de muitos outros que vão formando a espiral de alienação, pessoal, social e moral, que determina a ordem aparente do mundo: o homem preza o arbítrio das vaidades, suporta as múltiplas faces do engano, embarca em fábulas sobre diferenças hierárquicas, entra no artifício do consenso, lança-se no jogo de servidão e domínio do amor, porque não aceita o incondicionado da sua humanidade, essa insuportável liberdade metafísica, tão radical que se pode negar a si mesma. Neste trabalho de reconstrução da falha de ser, nesse projetar de uma plenitude semelhante ao eterno retorno da Natureza, vaidade e amor são os processos por excelência do reconhecimento, antes de figurarem como virtudes ou vícios. Com eles recriamos uma imagem de humanidade de acordo com as nossas preferências: com a vaidade supomos atributos imaginários; com o amor, transmutamos sensibilidade em sentimento ( $\mathrm{RVH}, \S 94)$. Neste esforço pesa, uma vez mais, o abismo que a reflexão matiana, diferentemente de um simples moralizador, recusa colmatar, pois, como sustenta, "quantas vezes buscar o precipício é o único meio de o evitar" (RVH, §80). Consequentemente o paradoxo guarda toda a sua eficácia: por mais espelhos que o homem venha a criar com o intuito de compensar o vazio por via do caleidoscópio das representações e da ilusão de que algo está a acontecer, o homem permanece limite e tensão, saudade de si e esperança de um outro, puro efeito dramático do Tempo (RVH, §106).

Nesta evidência se enraíza a estratégia global, que preconiza para alterar o status quo: "para obrarmos bem, não temos mais do que consultar a natureza e fazer o contrário" (RVH, §75). A natureza instituída, entenda-se, que não a instituidora. Trata-se, ao limite, de refazer o mundo às avessas, ou seja, do lado realmente direito, em acordo com a Natura naturans, esquema produtivo de igualdade, liberdade e comunidade, que não se compadece com a lógica de fronteiras, como reforça ao lembrar que

nascem os homens iguais; um mesmo, e igual princípio os anima, os conserva, e também os debilita, e acaba. [...] O mundo não foi feito mais em benefício de, que de outros, para todos é o mesmo; e para uso dele todos têm igual direito, ou seja pela ordem da sua natureza, ou seja pela ordem da sua mesma instituição ( $R V H$, §79). 
Este ideário, no qual também é identificável uma crítica, mais ou menos velada, ao despotismo esclarecido, parece configurar, consequentemente, uma organização política diversa, talvez uma forma de republicanismo contratualista como aquela que proporá, dez anos depois, Jean-Jacques Rousseau. Essa hipótese estaria em sintonia com aquela que enunciamos sobre a antecipação de uma ética da autenticidade, na Carta sobre a Fortuna, igualmente materializada na filosofia do genebrino. Contudo, Matias Aires não desenvolveu um tal programa político, limitando-se a deixar alguns elementos que possibilitam a reconstituição desse almejo, no qual não cabe identificar o prenúncio de uma solução revolucionária, mas a coerência de uma filosofia política baseada numa antropologia e numa ética universais. Para além do mais, tratando-se de revelar o positivo do que só é dado como negatividade, há que ter sempre a cautela, sobre a perceção intrinsecamente confusa que obsta à visão do outro lado do espelho, recomendada pelo próprio autor: "quando nos parece que a nossa vista rompeu a nuvem, e que o nosso discurso rompeu o embaraço, então é que estamos cegos, e então é que erramos mais" $(\mathrm{RVH}, \S 80)$.

O que cabe reconhecer é que as Reflexões, ao levarem ao extremo a exploração de um pessimismo metafísico, decorrente da noção de uma vacuidade última que assiste a uma existência temporal que tem de se constituir eticamente por entre representações ficcionadas e estados disposicionais carentes de substancialidade, induzem a ideia da necessidade de encontrar uma formar de quebrar esse círculo, ou pelo menos de alterar o seu centro, que possa figurar como um princípio razoável de felicidade. A questão que se põe é a de saber se essa saída corresponde à recomposição da sociedade política, "enquanto só no plano político da comunidade a natureza humana encontra verdadeira consumação e, permanecendo em si mesma como é, alcança pacificação para as aporias que intrinsecamente a dilaceram" (MESQUITA, 1998, p. 171), ou se depende de uma solução mais individualista, "abrindo um novo horizonte, o horizonte da verdadeira espiritualidade, que conduz à felicidade interior" (REAL, 2016, p. 316).

Com toda a probabilidade, nem uma, nem outra, isoladamente, uma e outra, como dois desfechos complementares. Esta nossa reserva advém da ausência de uma doutrina positiva que dê corpo ao que, em ambas, é sugerido pelas tensões do tracejamento negativo. Essa falta, que já apontámos no que respeita à doutrina social e política proporcionada pelas Reflexões, pode igualmente ser verificada na Carta. Com efeito, ainda que a retomada de alguns princípios fundamentais das éticas helenísticas, em particular da estoica, nos permita proceder à ideação de uma hermenêutica do sujeito, assente no cuidado de si, são as etapas preparatórias que avultam nesse escrito: o amor fati, com a consequente resignação sobre o alheamento da fortuna; o conhecimento de si, como reconhecimento dos limites e das capacidades próprias e condição da conciliação consigo; o abandono da mundanidade por via do isolamento forçado, na base de qualquer expectativa de virtude e sobretudo de uma liberdade superior.

Certamente que uma sociedade mais conforme à natureza constituiria um contexto mais favorável à realização da eticidade, minorando os efeitos perversos das vaidades opressoras e das paixões avassaladoras, mas seria contrário ao exposto pelo autor imaginar que esse novo regime não gerasse as suas vaidades e as suas paixões próprias. Também decorre do propósito crítico da obra que seria improcedente pensar uma antropologia política que não assentasse na transformação moral dos indivíduos. Por sua vez, o ideal do refúgio na cidadela do eu só ocorre depois de esgotada a esperança na fortuna e, em boa verdade, mantém-se numa 
certa expectativa de retorno ao convívio social, como fica patente na seguinte passagem: "Não duvido, que se ua fortuna mais brilhante me buscasse, eu a recebesse alegremente mas não sem sobressalto pelo descostume" (CF, p. 209). Ainda, a felicidade buscada nas formas da ataraxia ou da apatia resulta, menos numa satisfação plena ou numa espiritualização consumada, do que numa prevenção de efeitos nefastos, nomeadamente aqueles que se ligam à antecipação da morte: "quero deixar o mundo antes que o mundo me deixe. Quero antecipar-me já, para não estranhar depois" (CF, p. 208). Nada que surpreenda, tendo em conta a sociabilidade natural do homem, de que o reconhecimento pela vaidade e pelo amor testemunham.

$\mathrm{Na}$ verdade, o que prevalece em ambas as vias, delimitando o respetivo alcance, é a mesma experiência do tempo que temos vindo a salientar. Esta, pensada com seriedade filosófica, impede a proposta de qualquer solução definitiva ou absoluta, deixando apenas margem para que se pondere o conveniente e o inconveniente, os proègmena, em função do critério constituído pela própria temporalidade:"Bem sei que tudo no Mundo é transitório, porém entre as mesmas cousas que vão passando, alguas passam mais depressa do que outras; em uas há tempo de se verem, em outras não [...] a mesma vida é um verdadeiro transito, mas com certa e determinada duração" (CF, p. 201-202).

Matias Aires traça um quadro que se quer realista da nossa humanidade, mas, na medida em que este depende de um fundamento sem fundo, mesmo quando alvitra uma alternativa, deixa o homem entregue a si mesmo, na busca de um sentido para uma existência por justificar. Nesta indecisão, assim como no trânsito entre ética, moral e política, manifesta a modernidade do seu filosofar.

\section{Referências}

MATIAS AIRES. Reflexões sobre a Vaidade dos Homens e Carta sobre a Fortuna. Prefácio de António Pedro Mesquita. Fixação do texto, notas e posfácio de Violeta Crespo Figueiredo e Jacinto do Prado Coelho. Lisboa: INCM, 2005.

MATIAS AIRES. Problema de Arquitectura Civil. Lisboa: Oficina António Rodrigues Galhardo, 1778.

BERNARDO, L. M. A. V. Aprendizagens da Relatividade: as Experiências Químicas de Matias Aires. Revista da Faculdade de Ciências Sociais e Humanas, n. 19. Lisboa: Colibri, 2007. p. 127-143.

BERNARDO, L. M. A. V. Aventuras de Diófanes (1752), un avatar des Aventures de Télémaque écrit sous pseudonyme par Teresa Margarida da Silva Orta. In: PRÉYAT, F. (Ed.). Femmes des AntiLumières, Femmes apologistes. Études sur le 18e siècle, vol. 44. Bruxelles: Éditions de l'Université Libre de Bruxelles, 2016. p. 39-58.

BERNARDO, L. M. A. V. Matias Aires Ramos da Silva Eça. In: SIRGADO GANHO, M. (Coord.). Dicionário Crítico de Filosofia Portuguesa. Lisboa: Temas e Debates; Círculo de Leitores, 2016. p. 351-356.

BERNARDO, L. M. A. V. Matias Aires: Reflexões sobre a Vaidade dos Homens (1752). In: SIRGADO GANHO, M. (Coord.). Dicionário Crítico de Filosofia Portuguesa. Lisboa: Temas e Debates; Círculo de Leitores, 2016. p. 351-356.

BERNARDO, L. M. A. V. Metafísica dos Materiais: o Problema de Arquitectura Civil de Matias Aires. Convergências e Afinidades: Homenagem a António Braz Teixeira. Lisboa: Centro de Filosofia da Universidade de Lisboa; Centro de Estudos de Filosofia da Faculdade de Ciências Humanas da Universidade Católica Portuguesa, 2008. p. 459-471. 
LAFOND, J. (Dir.). Moralistes du XVIle Siècle: de Pibrac à Dufresny. Paris: Robert Laffont, 1992.

LÉVY, C. Les Philosophies hellénistiques. Paris: Librairie Générale de France, 1997.

MESQUITA, A. Homem, Sociedade e Comunidade Política: o Pensamento Filosófico de Matias Aires. Lisboa: INCM, 1998.

PAIM, A. As Luzes no Brasil. História do Pensamento Filosófico Português. v. III. Lisboa: Caminho, 2001.

REAL, M. A Ética da Felicidade em Carta sobre a Fortuna de Matias Aires. In:TEIXEIRA, A.; SANTOS, O.; EPIFÂNIO, R. (Coord.). Luís António Verney e a Cultura Luso-Brasileira do seu Tempo. Lisboa: Mil e DG Edições, 2016. p. 306-319.

REAL, M. Matias Aires: as Máscaras da Vaidade. Lisboa: Sete Caminhos, 2008.

ROMANO, C. Être soi-même: une autre histoire de la philosophie. Paris: Gallimard, 2019.

\section{Sobre o autor}

Luís Manuel A. V. Bernardo

Doutor em Filosofia pela Universidade Nova de Lisboa. Professor da Faculdade de Ciências Sociais e Humanas da Universidade Nova de Lisboa.

Recebido em: 22/08/2020.

Aprovado em: 25/09/2020.
Received: 22/08/2020.

Approved: 25/09/2020. 